\title{
Ship-to-Ship Collision Analyses Based on Functional Resonance Analysis Method
}

\author{
๑ I I Gde Manik Sukanegara Adhita, ( Masao Furusho
}

Kobe University, Graduate School of Maritime Sciences, Kobe, Japan

\begin{abstract}
This paper discusses the role of human performance variability in ship-to-ship collisions. Accordingly, an analysis was carried out based on the functional resonance analysis method (FRAM). A ship-to-ship collision report from Indonesia was used to generate the FRAM model for ship-ship encounters. This model was formed using six functions: maneuvering, watchkeeping, bridge communication, bridge-to-bridge communication, bridge-to-port communication, and engine control. Using FRAM, the cause of the collision accident can be determined based on the results of this analysis. This study emphasizes that the emergence of unwanted outcomes results from the unique interaction of the unexpected variability performance of functions between two ships during encounter situations. The resonance phenomenon explained how this unique interaction amplifies the effect of ship operation, performance variability. The use of FRAM could elucidate the complexity in ship operation and provide a more in-depth analysis for ship-to-ship collision accidents.
\end{abstract}

\section{Keywords}

Functional resonance analysis method, Human reliability, Safety-II, Ship-to-ship collision, Maritime accident

\section{Introduction}

Socio-technical systems, such as a ship, involve complex integration between social (human) and technical components. Each component is expected to function properly every day and meet the desired system goals while ensuring safety onboard. According to the Safety-I perspective, safety is defined as the emergence of an expected event in the system [1]. In contrast, risk is the condition when expected events do not occur. Risk is defined as something unfavorable that causes system failure. The purpose of investigating an accident from the point of view of the Safety-I perspective is to find the cause of that accident and then try to eliminate or create a barrier to it. From this perspective, human error is a critical factor in the occurrence of accidents.

Several prior studies have analyzed human factors regarding situational awareness in ship-to-ship collisions [2-4]. These studies were trying to determine how human error affects the occurrence of ship accidents. One study found that $71 \%$ of human error in maritime accidents is affected by poor situational awareness [3]. Furthermore, research regarding situational awareness to prevent shipto-ship collisions has been done by proposing a model of ship encounter situations to define a risk perception among two ships [5]. Related research has been done by Chauvin and Lardjane about situational awareness. They analyzed the actual decision made by the watch officer to understand the cognitive processes involved in normal ship interaction situations. Besides, they also studied the importance of Bridge Resource Management with a pilot onboard in restricted waters and decisions taken by the captain in critical conditions to enhance situational awareness [2]. Researchers also found that decision-making errors during sailing are caused by three things: a lack of information, incorrect expectations, and an incorrect judgment about the level of attentiveness required [6,7]. However, all of these studies focus only on a single major cause that has the highest contribution to the occurrence of the ship-to-ship collision.

Human error is not the cause of accidents; however, humans play a role in the occurrence of accidents, and their actions are important [8]. Furthermore, technological advancement 
increases the complexity of the system. Humans work according to how they have been trained, but they also tend to adapt and adjust their functioning as per the work requirements. Humans also interpret procedures by associating them with working conditions. However, to cope with this complexity of human behavior, mindsets need to be changed [9].

A systemic model views the accident as the emergence of unusual dependencies within the performance of the system [8]. Failure can be regarded as a variation in the system performance, wherein erraticism of the functional components can be potentially useful or harmful. These variabilities will always exist, no matter what we do. Hence, rather than looking for causes where only a few things go wrong, it is more important to focus on what usually happens in everyday performance when everything goes right. Subsequently, this idea is called the Safety-II perspective.

The functional resonance analysis method (FRAM) was first introduced as a model [10]; later, it was updated and reintroduced as a method [11]. This method was developed to achieve the safety definition listed in the Safety-II perspective. FRAM has been widely used in the field of safety and resilience [12-15]. In the maritime field, a study using FRAM has been conducted to re-analyze the capsizing of the MV Herald of Free Enterprise [16]. Other studies also used FRAM to evaluate the variabilities of system functions in the case of Prestige oil spill [17]. Furthermore, FRAM has been used to model the everyday performance of vessel traffic services to understand resilience from a work-asdone perspective [18].

According to the European Maritime Safety Agency annual report regarding navigational casualties, collision accidents contribute $13 \%$ of all maritime casualty events (11 categories) [19]. Therefore, it is become essential to provide a better understanding of ship collision accidents. In this paper, the Safety-II point of view is used through FRAM to provide different perspectives of the occurrence of a ship-to-ship collision. FRAM was used to present dependency among key functions during ship encounter situations. It could show that the accidents occurred due to a combination of unexpected variability from several functions rather than a single primary cause. This study aimed to determine how resonance effect could amplify the variability performance of functions in the system.

\section{Ship-to-Ship Collision Accident Data}

The maritime sector is a vital industry for global economic trade. The ship is an essential component of the maritime sector. Around $80 \%$ of our daily goods are transported by ships [20]. When the ship fails, it has a social, financial, and environmental impact on the transport process. It is necessary to achieve successful sailing activities, maintain the stability of the economy, and protect the ocean environment and people who work on the ship.

Ship-to-ship collisions vary depending on the types of ships involved, weather conditions, location, time, etc. Since it is difficult to generalize their situations, this research limited the scope of analysis to accidents involving merchant ships only. An accident that occurred in Indonesia was chosen for analysis. This report included two ship-to-ship interactions, one of which was successful, and the other was unsuccessful. This report was ideal for presenting the FRAM perspective, wherein success and failure are regarded coming from the same source.

\subsection{Case Study}

On June 28, 2015, a ship-to-ship collision occurred in Surabaya West Access Channel (SWAC), Indonesia. The encounter situation involved three cargo ship, namely, Ship A, B, and C [21]. The story began when Ship A sailed by Pilot A embarked at about 22:00 local time. At the time, the pilot, master, and some officers were onboard. Her heading was $198^{\circ} \mathrm{T}$ toward International Container Terminal in the SWAC. Conversely, at about 22.52 local time, Ship B began to sail from Nilam Port in Gresik toward the Kalbut Port in Situbondo. There were four people onboard: Pilot, master, chief officer, and helmsman. Since the accident only involved Ships A and B, the detailed information of Ship C is not included in the report. At that time, Ship C was also sailing on SWAC with master and helmsman onboard. At approximately 23:12 local time, Pilot A realized the existence of Ships C and B. Quickly, Pilot A communicated with Ships $B$ and $C$ regarding passing agreement. Pilot A suggested passing red-to-red with Ship B and green-togreen with Ship C. The first interaction occurred between Ship A and Ship C, wherein the collision was successfully avoided. Then, right behind Ship C, Ship B was ready for the second encounter with Ship A. However, shortly before this second interaction, Pilot A and the crew of Ship A lost their awareness and allowed Ship A to sail into shallow water. The rudder failed, and Ship A lost control of her course. Pilot A quickly took action by informing the situation to Master B in the hope that Ship B could adjust to avoid collision with Ship A. Unfortunately, this time, the distance between Ships A and B was too close; hence, the collision could not be avoided.

\section{Functional Resonance Analysis Method (FRAM)}

FRAM is a recently developed method for analyzing complex socio-technical systems. The essential feature of this method is a function necessary to explain the activity of a system 
where the functions are mutually dependent. System activity is modeled in terms of how the system performs to ensure that it performs reliably and systematically [11]. FRAM is based on four basic principles: the principle of equivalence of successes and failure, the principle of approximate adjustments, the principle of emergence, and the principle of functional resonance.

The principle of equivalence of successes and failures states that whether things go right or go wrong, the events arise from the same source, which is the everyday work of the system. While a person is working, his or her performance serves as a source for the system to produce either good or bad outcomes. Humans also can adjust their performance in a dynamic work environment. Here the principle of the approximate adjustment was applied. In the actual work environment, performance needs to be variable to help the system successfully adapt to the operational situation. The principle of emergence shows that system outcome is explained as the emergence of variability in performance from everyday adjustment rather than a result of specific cause-effect chains. The last principle, the principle of functional resonance, describes the ability to detect the unintended interaction amid the variability of function performance through the phenomenon of resonance.

FRAM's functions are divided into three main groups: human, technological, and organizational. Functions describe activities or actions (more than just a task) and show what needs to be accomplished, regardless of the method used. The function has six different aspects, as shown in Figure 1 [11]: input (I), output (O), precondition $(\mathrm{P})$, resource $(\mathrm{R})$, time $(\mathrm{T})$, and control (C) [10]. Descriptively, the I is information, matter, or command used by the function to produce the $O$. The $\mathrm{O}$ describes the action of the function after processing information from other aspects, such as processing instructions from the I. The P specifies the condition that must be achieved before the function starts. However, this does not mean that this signal can start the function by itself. A R is described as something that the function needs while it is being carried out; for example, a spoon for eating ice cream. $\mathrm{C}$ refers to something that directs the function while producing the desired O. Finally, time represents an action that consumes time, which can affect the performance of a function.

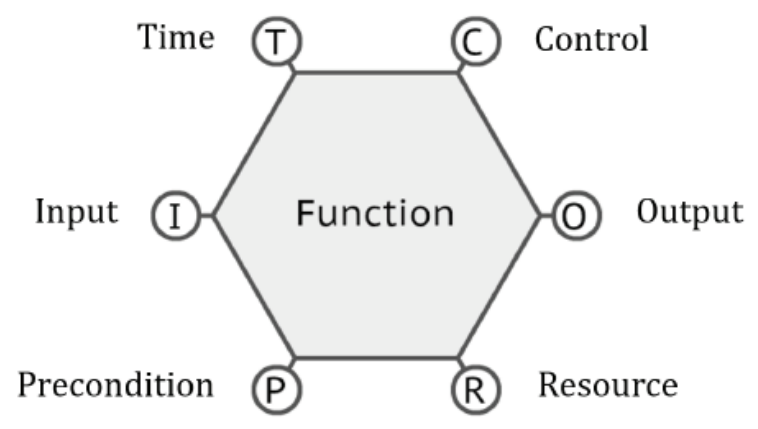

Figure 1. FRAM hexagonal function representation [11]

FRAM: Functional resonance analysis method

\subsection{Method Implementation}

This research used the term sailing to describe the ship's activity moving through the shipping lane for transferring goods from one port to another port. There are three steps in order to conduct the analysis. First, the analysis involved dividing the onboard activity of an officer during sailing into six main functions, as shown in Figure 2, consist: maneuvering (MAN), watchkeeping (WAT), bridge communication (BCM), bridge-to-bridge communication (BBC), bridge-to-port communication (BPC), and engine control (ECN).

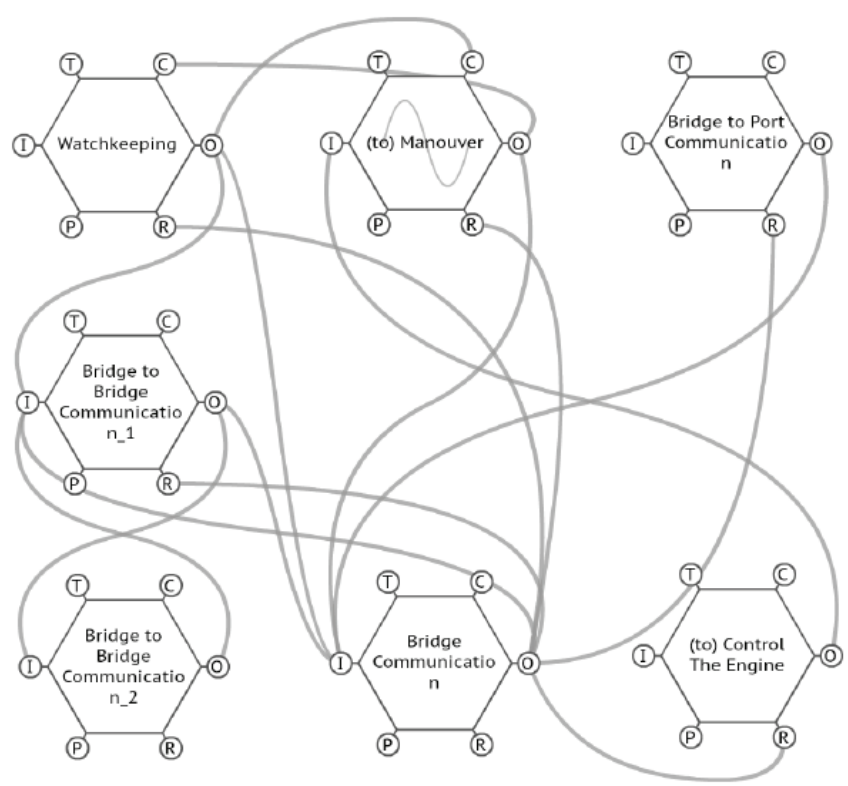

Figure 2. FRAM general model of human activities during ship-ship encounter

FRAM: Functional resonance analysis method, T: Time, I: Input, O: Output, C: Control, P: Precondition, R: Resource 
MAN describes all activities related to changing the ship's course, which is usually completed by the helmsman but can also be fulfilled by a master or officer on duty or pilot onboard under special conditions. Both direct lookout and lookout through electronic devices (WAT) are used to observe the vicinity of the ship (utilizing direct and electronic devices). BCM is associated with bridge team activities, which also include a pilot (supplementary). This activity describes the on duty crew interaction during sailing. On the bridge, at least one officer and a helmsman are usually present. In some conditions, an additional crew is required on the bridge; for example, the shipmaster should be ready on the deck near the port or channel. BBC describes the interaction between two or more ships to exchange information. Essentially, BBC, BPC, and vessel traffic services (VTS) communication are the same, but bridge-to-port and VTS communications are interactions established between the ship and shore facilities (VTS and port authorities). ECN is an activity carried out under specific situations, such as an emergency condition that forces the ship to lower its service speed or stop the engine.

The second step is to present potential couplings among the functions to describe the system. Figure 3 depicts the integration models of these eight functions. It is essential to state the upstream and downstream functions to describe the temporal relationship between them. This state is explained, as shown in Table 1, where function 1 contains the upstream functions and function 2 contains the downstream functions. It is also crucial to highlight that the relationship between functions does not represent the sequence of actions. The model was built based on the accident report used in this research (work-as-done) combined with the ideal condition imagined by the authors (work-as-imagine).

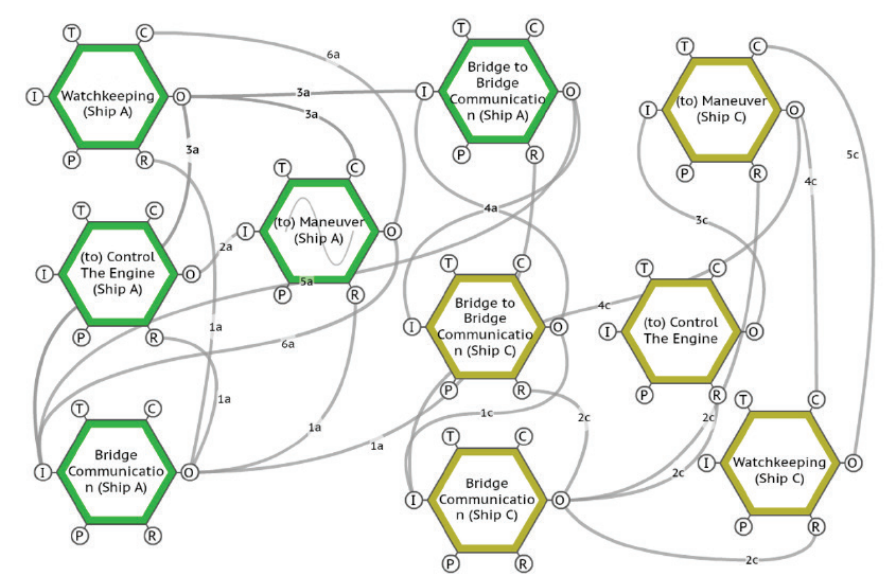

Figure 3. FRAM model for the first meeting between Ship A and Ship C

FRAM: Functional resonance analysis method, T: Time, I: Input, O: Output, C: Control, P: Precondition, R: Resource
Table 1. Function description for the general model

\begin{tabular}{|c|c|c|c|}
\hline Code & Function 1 & Function 2 & Information \\
\hline \multirow{5}{*}{1} & \multirow{5}{*}{$\mathrm{BCM}(0)$} & MAN (R) & Officer on duty \\
\hline & & ECN (R) & Officer on duty \\
\hline & & WAT (R) & Officer on duty \\
\hline & & $\mathrm{BBC}(\mathrm{R})$ & Officer on duty \\
\hline & & $\mathrm{BPC}(\mathrm{R})$ & Officer on duty \\
\hline 2 & $\operatorname{ECN}(0)$ & MAN (I) & Standby \\
\hline \multirow{3}{*}{3} & \multirow{3}{*}{ WAT (0) } & MAN (R) & $\begin{array}{l}\text { Observation (electronic device/ } \\
\text { direct) }\end{array}$ \\
\hline & & BCM (I) & $\begin{array}{l}\text { Realized the existence of any } \\
\text { suspicious ship }\end{array}$ \\
\hline & & $\mathrm{BBC}(\mathrm{I})$ & $\begin{array}{l}\text { Realized the existence of any } \\
\text { suspicious ship }\end{array}$ \\
\hline \multirow{2}{*}{4} & BBC_1 (0) & BBC_2 (I) & Make contact/confirmation \\
\hline & BBC_2 (0) & BBC_1 (I) & Make contact/confirmation \\
\hline 5 & $\mathrm{BBC}(0)$ & BCM (I) & Confirm agreement \\
\hline \multirow{2}{*}{6} & \multirow{2}{*}{ MAN (O) } & BCM (I) & Altering the ship's course \\
\hline & & WAT (C) & Altering the ship's course \\
\hline 7 & $\mathrm{BPC}(0)$ & BCM (I) & Information \\
\hline \multicolumn{4}{|c|}{$\begin{array}{l}\text { MAN: Maneuvering, ECN: Engine control, WAT: Watchkeeping, BCM: Bridge } \\
\text { communication, BBC: Bridge-to-bridge communication, BPC: Bridge-to-port } \\
\text { communication, O: Output, R: Resource, I: Input, C: Control }\end{array}$} \\
\hline
\end{tabular}

The third step is to define the functional resonance based on the dependencies among the functions. Functional resonance is defined as a detectable signal that emerges from an unintended interaction of performance variability between multiple functions. In FRAM representation, couplings are generally many-to-many (rather than oneto-one). For instance, a bridge team communication (code 1) has an $\mathrm{O}$ of five functions that serve as a R. Similarly, a function can also have multiple Is from several functions in the form of I, T, Rs, etc. Through this connection, a resonance effect can describe function interactions that either produces damping or amplifying effects for the system performance variability, resulting in desired or unwanted outcomes.

\section{Ship-to-Ship Collision Analyses Results}

This case study was divided into two parts for analysis. The first part was the first encounter that occurred between Ship A and Ship C, as depicted in Figure 3. The second part was the meeting that occurred between Ships A and B, as shown in Figure 4. The model was built using the report in subsection 2.1 and a step from section 3. It consisted of five functions for each ship, without a BPC. These two models present the dependencies of the function that produce both desired outcome (success to avoid the collision) and undesired outcome (failed to avoid the collision). 


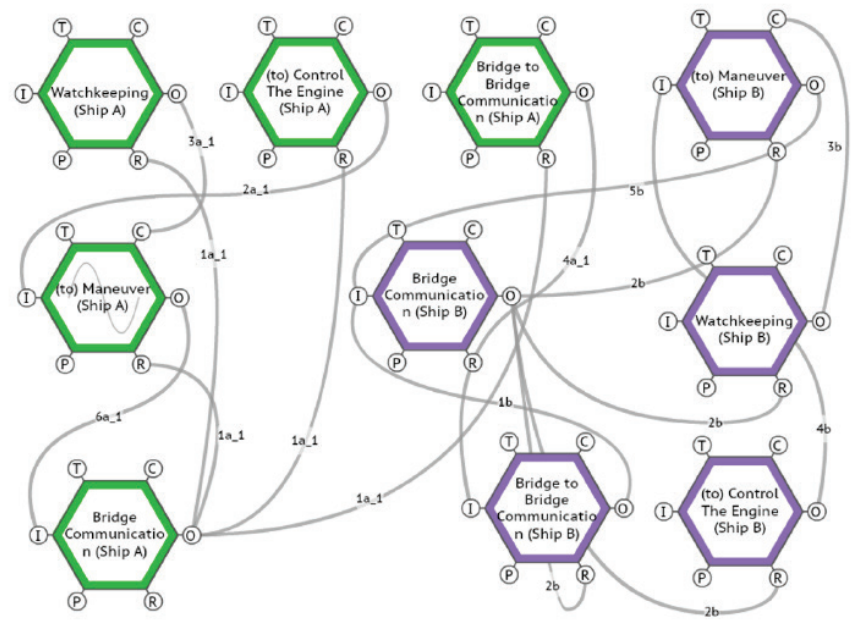

Figure 4. FRAM model for the second meeting between Ship A and Ship B

FRAM: Functional resonance analysis method, T: Time, I: Input, O: Output, C: Control, P: Precondition, R: Resource

Table 2 presents detailed information shown in Figure 3. At the first meeting, no accidents occurred. Both Ships A and $C$ passed each other safely. Figure 3 shows that both BCM functions (1a, 2c) from Ships A and C emerged on time and were acceptable. Here, BCM 0 serves as a R for MAN, ECN, BBC, and WAT. Through these connections, the expected variation of BCM provides a damping effect to the performance variability of its downstream function. The expected variation in WAT (proper watchkeeping) and BBC (Pilot A's decision to make verbal communication with Ships B and C) can emerge smoothly. This emergence also provided positive feedback for BCM.

Everything was on point until Pilot A took action to respond to the passing agreement by altering Ship A's course. At this point, MAN_A (6a) appears to have executed slightly imprecise. BCM receives the 0 from this function as I. However, for the first meeting, this improper emergence had no significant impact on system performance. Here, we can see that Pilot A and Ship A's crew awareness (1a and $3 \mathrm{a}$ ) and the decision to make verbal communication (4a) dampened the amplifying effect from MAN_A and muffled the variability of Ship A's performance. This intended interaction of useful variation from these three functions made the variability performance of Ship A easier to manage. Hence, Ships A and C safely pass each other. Ship A should pass Ship B shortly after interacting with Ship C. Figure 4 depicts the FRAM model for the second meeting with detailed information shown in Table 3. Here, Ship A failed to avoid collision with Ship B. As previously stated, the presumed unintended action first occurred at MAN_A (6a). Using the phenomenon of resonance, when two or more objects
Table 2. Function description of the model for the first meeting

\begin{tabular}{|c|c|c|c|}
\hline Code & Function 1 & Function 2 & Description \\
\hline \multirow{4}{*}{$1 \mathrm{a}$} & \multirow{4}{*}{ BCM_A (0) } & MAN_A (R) & Officer on duty \\
\hline & & ECN_A (R) & Officer on duty \\
\hline & & WAT_A (R) & Officer on duty \\
\hline & & BBC_A (R) & Officer on duty \\
\hline $2 \mathrm{a}$ & ECN_A (O) & MAN_A (I) & Standby \\
\hline \multirow{3}{*}{$3 a$} & \multirow{3}{*}{ WAT_A (O) } & MAN_A (R) & $\begin{array}{c}\text { Observation } \\
\text { (electronic device/direct) }\end{array}$ \\
\hline & & BBC_A (I) & $\begin{array}{l}\text { Realized the existence of any } \\
\text { suspicious ship }\end{array}$ \\
\hline & & BCM_A (I) & $\begin{array}{l}\text { Realized the existence of any } \\
\text { suspicious ship }\end{array}$ \\
\hline \multirow{2}{*}{$4 a$} & BBC_A (0) & BBC_C (I) & Make contact/confirmation \\
\hline & BBC_C $(0)$ & BBC_A (I) & Make contact/confirmation \\
\hline $5 a$ & BBC_A (0) & BCM_A (I) & Confirm agreement \\
\hline \multirow{2}{*}{$6 a$} & \multirow{2}{*}{ MAN_A (O) } & BCM_A (I) & Altering the ship's course \\
\hline & & WAT_A (C) & Altering the ship's course \\
\hline $1 \mathrm{c}$ & BBC_C $(0)$ & BCM_C (I) & Confirm agreement \\
\hline \multirow{4}{*}{$2 \mathrm{c}$} & \multirow{4}{*}{ BCM_C (O) } & MAN_C (R) & Officer on duty \\
\hline & & ECN_C (R) & Officer on duty \\
\hline & & WAT_C (R) & Officer on duty \\
\hline & & BBC_C (R) & Officer on duty \\
\hline $3 c$ & ECN_C (O) & MAN_C (I) & Standby \\
\hline \multirow{2}{*}{ 4c } & \multirow{2}{*}{ MAN_C $(0)$} & BCM_C (I) & Altering the ship's course \\
\hline & & WAT_C (C) & Altering the ship's course \\
\hline $5 c$ & WAT_C (O) & MAN_C (R) & $\begin{array}{c}\text { Observation } \\
\text { (electronic device/direct) }\end{array}$ \\
\hline
\end{tabular}

MAN: Maneuvering, ECN: Engine control, WAT: Watchkeeping, BCM: Bridge communication, BBC: Bridge-to-bridge communication, BPC: Bridge-to-port communication, O: Output, R: Resource, I: Input, C: Control, A: Ship A, C: Ship C

coincide, they vibrate at the same frequency, which can increase the vibration amplitude of one of these objects. When this condition continues to occur within a certain period, the amplitude becomes larger and may cause severe damage or even destroy the system.

The imprecise variation of MAN_A (6a) was followed by an imprecise variation of BCM_A (1a_1) and WAT_A (3a_1). The imprecise variation of BCM_A and WAT_A functions was proven by Pilot A completely lost his awareness (nor Ship A's crew onboard), and all crew onboard do not properly work together as a team. The unintended interaction caused by unexpected variability of these three functions coincidentally became resonant, resulting in large variability of system performance. Ultimately it caused an unexpected event to emerge; in this case, the rudder of Ship A hit the obstacle and failed. 
Table 3. Function description of the model for the second meeting

\begin{tabular}{|c|c|c|c|}
\hline Code & Function 1 & Function 2 & Description \\
\hline \multirow{4}{*}{ 1a_1 } & \multirow{4}{*}{ BCM_A (O) } & MAN_A (R) & Officer on duty \\
\hline & & ECN_A (R) & Officer on duty \\
\hline & & WAT_A (R) & Officer on duty \\
\hline & & BBC_A (R) & Officer on duty \\
\hline $2 \mathrm{a} \_1$ & ECN_A (O) & MAN_A (I) & Standby \\
\hline \multirow{2}{*}{ 3a_1 } & \multirow{2}{*}{ WAT_A (0) } & MAN_A (R) & $\begin{array}{c}\text { Observation (shallow water } \\
\text { undetected) }\end{array}$ \\
\hline & & BCM_A (I) & $\begin{array}{c}\text { Observation (shallow water } \\
\text { undetected) }\end{array}$ \\
\hline $4 a_{-} 1$ & BBC_A (0) & BBC_B (I) & Make contact/confirmation \\
\hline $6 a_{-} 1$ & MAN_A (O) & BCM_A (I) & Altering the ship's course (failed) \\
\hline $1 \mathrm{~b}$ & BBC_B (O) & BCM_B (I) & $\begin{array}{l}\text { Information (emergency } \\
\text { condition) }\end{array}$ \\
\hline \multirow{4}{*}{$2 \mathrm{~b}$} & \multirow{4}{*}{ BCM_B (O) } & MAN_B (R) & Officer on duty \\
\hline & & ECN_B (R) & Officer on duty \\
\hline & & WAT_B (R) & Officer on duty \\
\hline & & BBC_B (R) & Officer on duty \\
\hline $3 \mathrm{~b}$ & WAT_B (O) & MAN_B (R) & $\begin{array}{l}\text { Observation (electronic device/ } \\
\text { direct) }\end{array}$ \\
\hline $4 \mathrm{~b}$ & ECN_B (O) & MAN_B (I) & Stop the engine \\
\hline $5 b$ & MAN_B (O) & BCM_B (I) & $\begin{array}{l}\text { Altering the course (cannot stop } \\
\text { the ship) }\end{array}$ \\
\hline \multicolumn{4}{|c|}{$\begin{array}{l}\text { MAN: Maneuvering, ECN: Engine control, WAT: Watchkeeping, BCM: Bridge } \\
\text { communication, BBC: Bridge-to-bridge communication, BPC: Bridge-to-port } \\
\text { communication, O: Output, R: Resource, I: Input, C: Control, A: Ship A, B: } \\
\text { Ship B }\end{array}$} \\
\hline
\end{tabular}

On the other hand, Ship B experienced the same condition. Even though the information between Ships A and B was established regarding the passing agreement, Pilot B and Ship B's crew did not maintain their teamwork. This improper variation of BCM_B (2b) was later followed by the emergence of unexpected variability performance of WAT_B (3b) and ECN_B (4b). The 0 from BCM_B, WAT_B, and ECN_B is received by MAN_B as a R, C, and I. Through this unexpected interaction of functions result in an amplifying effect on the variability performance of Ship B; thus, Ship B was unable to take proper MAN action to overcome Ship A's condition. Both Ships, A and B, failed to avoid the risk of ship-to-ship collision.

\section{Discussions}

The FRAM has been widely used to provide a better understanding both for accident analysis or everyday operation analysis in the maritime field $[17,18]$. These studies elaborate on the use of functions and their performance variability to evaluate oil spill accidents and VTS operations. Besides, a study that evaluates dynamic factors in ship operations found that the combination of environmental factors and officer's situational awareness could significantly affect the ship operation [22]. In line with those studies, the present research uses functions and their performance variability to evaluate ship-to-ship collision accidents through FRAM. The analysis is advanced by presenting a FRAM model to present functions dependency for each ship. This research also found the interaction between the officer's situational awareness, ship MAN, and communication play an essential role in ship safety.

The FRAM analysis shows how performance variability of different functions within the same dependencies of functions (Figure 3 and 4 ) could produce different outcomes for ship encounter situations. In the first encounter, unwanted variability performance from MAN_A 0 that was received by BCM_A as I could dampen by wanted variability performance from the 0 of WAT_A and BBC_A that was also received by BCM_A as I. Thus, BCM_A can still produce an acceptable $\mathrm{O}$ for its downstream functions. In contrast, the second encounter shows how dependency between the 0 from BCM_B, WAT_B, and ECN_B that was received by MAN_B as a $\mathrm{R}, \mathrm{C}$, and I, respectively, became resonant and amplified the variability performance of MAN_B and MAN_A, resulting in a collision accident for both Ships A and B.

This analysis clearly shows how things go wrong, and things go right are happens exactly in the same way, in this case, from the everyday work (performance variability) itself [11]. This study also shed light on the interaction among officer's actions during ship-ship encounter situations that create either safe or dangerous encounter situations. The results found that the collision accident occurred not due to improper variation from one function but as a result of the unique interaction of unexpected variability performance between many functions [16]. In this case, the emergence properties are crucial in describing the relationships among ship operation functions. The interaction of unexpected variability performance between various functions in everyday ship operation can produce a new outcome beyond their functions capacity. Through functional resonance, the FRAM function and aspect show how the dependency among functions can produce either amplifying or damping effect on the variability of the system performance-the higher the variability performance of the system, the more difficult it is to manage their outcomes.

FRAM considers two phenotype configurations in a simple solution to categorize variability manifestation, namely: timing and precision. Concerning functions that have multiple potential couplings, such as BBC and WAT, are the points where variability can easily amplify and spread. This implies that these functions naturally exhibit highly variable performances. In terms of timing and precision, 
slight differences in response can cause the system to produce different results.

In contrast, ECN is a function with the lowest variability performance. These functions became active only after the conditions required for the preceding functions were met. Nonetheless, this function is necessary and essential. When the situation becomes dangerous, this function can be used to neutralize the amplifying effect of the system performance and provide a better resolution. Besides, $\mathrm{BBC}, \mathrm{BPC}$, and MAN have a moderate levels of variability in function performance. $\mathrm{BBC}$ and $\mathrm{BPC}$ are more reactive to timing, while MAN is more reactive to precision. A slight distortion of these functions is easier to overcome when others emerge correctly.

Some combinations allowed one function to become distorted if the others emerged precisely in place. The resonant effect can slightly amplify the system performance variability; however, in general, it dampens. For instance, the first encounter between Ships A and C appears to have performed smoothly. The analysis found a slight distortion in the MAN function of the performance of Ship A, as shown in Table 4. This slight distortion did not affect the first encounter.

Table 4. Key functions that produce a damping effect at the first encounter

\begin{tabular}{|c|c|c|c|}
\hline \multirow{2}{*}{ Code } & \multirow{2}{*}{ Function } & \multicolumn{2}{|c|}{ Variability performance classification } \\
\cline { 3 - 4 } & & Time & Precision \\
\hline 1a & BCM_A & Acceptable & Precise \\
\hline 3a & WAT_A & Acceptable & Precise \\
\hline 4a & BBC_A & Acceptable & Precise \\
\hline 6a & MAN_A & Acceptable & Slightly imprecise \\
\hline \multicolumn{4}{|c|}{ WAT: Watchkeeping, BCM: Bridge communication, BBC: Bridge-to-bridge } \\
communication, MAN: Maneuvering, A: Ship A
\end{tabular}

On the other hand, some combination of variability performance can completely distort the system. For instance, the unexpected variability performance of MAN function in Ship A that occurred in the first encounter situation continues to consume. This minor distortion becomes more prominent over time and has a significant impact on the second encounter. Together with the unwanted variations in WAT and BCM functions, as shown in Table 5, both in Ships A and B become resonant and amplify system performance variability. This condition forces the system to produces a vast amount of possible outcomes. It causes the unexpected outcome easier to emerge. Hence, Ships A and B in the second encounter cannot avoid the collision.
Table 5. Key functions that produce an amplifying effect at the second encounter

\begin{tabular}{|c|c|c|c|}
\hline \multirow{2}{*}{ Code } & \multirow{2}{*}{ Function } & Variability performance classification \\
\cline { 3 - 4 } & & Time & Precision \\
\hline 6a & MAN_A & Acceptable & Slightly imprecise \\
\hline $1 \mathrm{a} \_1$ & BCM_A & Too late & Slightly imprecise \\
\hline 3a_1 & WAT_A & Too late & Imprecise \\
\hline 2b & BCM_B & Too late & Imprecise \\
\hline 3b & WAT_B & Too late & Imprecise \\
\hline WAT: Watchkeeping, BCM: Bridge communication, MAN: Maneuvering, A: \\
Ship A, B: Ship B \\
\hline
\end{tabular}

\section{Conclusion}

Through FRAM analyses, this study found that a single failure of function does not cause a ship-to-ship collision; rather, theunintended dependency of several malfunctionsthe interaction between WAT, BCMs, and MAN functionshave a negative impact on the system performance. FRAM analysis facilitated the review of dependencies through resonance phenomena. Function performance exhibited variations that were viewed as either useful or harmful to the system. The dependency among function variability was intended to produce a damping effect on each other. Hence, it was expected that the variability in the system performance would be as low as possible, and system outcomes were controlled. Unfortunately, it was found that the variable performance under certain circumstances is uncontrolled due to the resonance effect between functions. This resonance phenomenon amplified the variability in system performance and made the system difficult to control. In a ship-to-ship interaction, as discussed in this paper, FRAM has shown how the dependency between expected variability performance of each function can dampen the variability in the system performance and prevent the ship from colliding. However, a better understanding of everyday sailing performance is needed to recommend changes that enhance ship safety.

This study provides an in-depth analysis of ship-to-ship collision accidents through functions and their variability performance. Controlling the performance variability is key to managing the system outcome. Functions in the system are expected to emerge acceptably rather than precisely. Although precise action is required, an acceptable action is more likely to occur. Admittedly, human capacity allowed us to create this situation. In this work, FRAM showed excellent potential for ship-to-ship collision analysis by considering the interdependency between functions and searching for potential sources of functional resonance to overcome the emergence of unwanted variability in function performance. Moreover, it must emphasize that a missing function might 
exist due to a lack of information on the current accident report; thus, further analysis is needed to evaluate this matter. In the future, a quantification approach is also required to provide a better understanding of performance variability.

\section{Authorship Contributions}

Concept design: I.G.M.S. Adhita, M. Furusho, Data Collection or Processing: I.G.M.S. Adhita, M. Furusho, Analysis or Interpretation: I.G.M.S. Adhita, M. Furusho, Literature Review: I.G.M.S. Adhita, M. Furusho, Writing, Reviewing and Editing: I.G.M.S. Adhita, M. Furusho.

Funding: The authors declared that this study received no financial support.

\section{References}

[1] E. Hollnagel, "Risk + barriers = safety?," Safety Science., vol. 46, pp. 221-229, Feb 2008.

[2] C. Chauvin, S. Lardjane, G. Morel, J. P. Clostermann, and B. Langard, "Human and organisational factors in maritime accidents: Analysis of collisions at sea using the HFACS," Accident Analysis \& Prevention, vol. 59, pp. 26-37, Oct 2013.

[3] M.R. Grech, T. Horberry, and A. Smith, "Human error in maritime operation: analysis of accident reports using the leximancer tool," Proceedings of the Human Factors and Ergonomics Society Annual Meeting, vol. 46, pp. 1718-1722, Sept 2002.

[4] C. Chauvin and S. Lardjane, "Decision making and strategies in an interaction situation: collision avoidance at sea," Transportation Research Part F: Traffic Psychology and Behaviour. vol. 11, pp. 259-269, Jul 2008.

[5] J. Bin Yim, D. S. Kim, and D. J. Park, "Modeling perceived collision risk in vessel encounter situations," Ocean Engineering, vol. 166, pp. 64-75, Oct 2018.

[6] C. Nishizaki and T. Takemoto, "Error detection in the navigational watch based on the behavior analysis of navigators," The International Journal on Marine Navigation and Safety of Sea Transportation, vol. 9, pp. 163-168, Jun 2015.

[7] C. Nishizaki, T. Takemoto, and Y. Kunieda, "A characteristic of a navigator's situation awareness for crossing ships," The International Journal on Marine Navigation and Safety of Sea Transportation, vol. 11, pp. 109-114, Jun 2017.

[8] E. Hollnagel, "Understanding accidents - From root causes to performance variability," Proceedings of the IEEE 7th Conference on Human Factors and Power Plants, pp. 1-6, Feb 2002.
[9] E. Hollnagel, "Coping with complexity: past, present and future," Cognition, Technology \& Work, vol. 14, pp. 199-205, Dec 2011.

[10] E. Hollnagel and Ö. Goteman, "The Functional Resonance Accident Model," Proceedings Cognitive Systems Engineering Process plant, pp. 155-161, 2004.

[11] E. Hollnagel, FRAM: The Functional Resonance Analysis Method. Ashgate: England, 2012.

[12] P.V.R. De Carvalho, "The use of Functional Resonance Analysis Method (FRAM) in a mid-air collision to understand some characteristics of the air traffic management system resilience," Reliability Engineering \& System Safety, vol. 96, pp. 1482-1498, Nov 2011.

[13] C.J. Meeuwis, V. Steinmetz, J. F. Hamming, and S. W. A. Dekker, "A FRAM requirements analysis for Safety Differently investigations," Safety Scence, vol. 125, pp. 104653, Feb 2020.

[14] D. Nouvel, S. Travadel, and E. Hollnagel, "Introduction of the concept of functional resonance in the analysis of a nearaccident in aviation," 33rd ESReDA Seminar: Future challenges of accident investigation pp. 1-9, Aug 2007.

[15] R. Patriarca, J. Bergström, and G. Di Gravio, "Defining the functional resonance analysis space: Combining Abstraction Hierarchy and FRAM," Reliability Engineering \& System Safety, vol. 165, , pp. 34-46, March 2017.

[16] G. Praetorius, M. Lundh, and M. Lützhöft, "Learning from the past for pro-activity - are-analysis of the accident of the MV herald of free enterprise," Proceedings of the Fourth Resilience Engineering Symposium, pp. 217-226, Jun 2016.

[17] E. Salihoglu and E. Bal Beşikçi, "The use of Functional Resonance Analysis Method (FRAM) in a maritime accident: A case study of Prestige," Ocean Engineering, vol. 219, Jan 2021.

[18] G. Praetorius, E. Hollnagel, and J. Dahlman, "Modelling vessel traffic service to understand resilience in everyday operations," Reliability Engineering \& System Safety vol. 141, pp. 10-21, Sept 2015.

[19] EMSA, "Annual Overview Of Marine Casualties And Incidents 2020," European Maritime Safety Agency, 2020.

[20] United Nations Conference on Trade and Development, “Transport Newsletter Second Quarter 2008," no. 39, 2008.

[21] M. Safety, I. Report, I. Registered, S. Western, and A. Channel, "FINAL," no. June 2015, 2019.

[22] S. Göksu and Ö. Arslan, "Quantitative analysis of dynamic risk factors for shipping operations" Journal of ETA Maritime Science, vol. 8, pp. 86-97, April 2020. 